\title{
Experimental study on heat transfer of an engine radiator with $\mathrm{T}_{\mathrm{i}} \mathrm{O}_{2} /$ EG-water nano-coolant
}

\author{
Mohd Muzammil Zubair ${ }^{1} \cdot$ Md. Seraj $^{2} \cdot$ Mohd. Faizan $^{1} \cdot$ Mohd Anas $^{2} \cdot$ Syed Mohd. Yahya ${ }^{1}$ (i)
}

Received: 9 July 2020 / Accepted: 25 February 2021 / Published online: 6 March 2021

(C) The Author(s) 2021 OPEN

\begin{abstract}
Nanofluid as a transport medium displays a great potential in engineering applications involving heat transfer. In this paper, the execution of water and ethylene glycol-based $\mathrm{T}_{\mathrm{i}} \mathrm{O}_{2}$ nanofluid as a radiator coolant is resolved experimentally. The convective heat transfer coefficient of $\mathrm{T}_{\mathrm{i}} \mathrm{O}_{2} / \mathrm{EG}$-Water nanocoolant has been estimated and contrasted with the information acquired experimentally. Nanocoolant were set up by taking $25 \%$ ethylene glycol and $75 \%$ water with low volume concentration of $\mathrm{T}_{i} \mathrm{O}_{2}$ nanoparticles. All the experiments were led for the distinctive volume flow rates in the range going from 30 to $180 \mathrm{~L} / \mathrm{h}(\mathrm{LPH})$. The nanocoolant made to flow through curved radiator tubes in every experiment, so that it can exchange heat effectively. Result shows that increasing the volume flow rate of nanocoolant flowing in the radiator tubes, increases the heat transfer as well as the convective heat transfer coefficient of nanocooant. Maximum heat transfer enhancement of $29.5 \%$ was recorded for nanocoolant with $0.03 \%$ nanoparticle concentration as compared to water at $150 \mathrm{LPH}$. Apart from this nanoparticle concentration into the base fluid, no further enhancement in heat transfer has been observed at any volume flow rate.
\end{abstract}

Keywords Radiator - Nanocoolant · Ethylene glycol (EG) · Heat transfer coefficient

\section{Abbreviations}

$A_{c} \quad$ Cross-sectional area of tube, $m^{2}$

$A_{s} \quad$ Surface area of tube, $m^{2}$

$C_{p} \quad$ Specific heat, $\mathrm{J} / \mathrm{Kg}-\mathrm{K}$

$D_{h} \quad$ Hydraulic diameter, $m$

h Convective heat transfer coefficient, $W / m^{2}-K$

$\mathrm{L} \quad$ Length of the tube of radiator, $\mathrm{m}$

m Mass flow rate, $\mathrm{kg} / \mathrm{s}$

$\mathrm{Nu}$ Nusselt Number

Q Rate of heat transfer, $W$

Re Reynolds Number

\section{Greek symbols}

$\rho \quad$ Density, $\mathrm{Kg} / \mathrm{m}^{3}$

$\mu \quad$ Dynamic viscosity, $\mathrm{kg} / \mathrm{m} . \mathrm{s}$

$\phi \quad$ Volume Concentration

\section{Subscripts \\ in Inlet of radiator tubes \\ out Outlet of radiator tubes}

\section{Introduction}

One of the most vital challenges today is to utilize the available energy and to manage the wastage of heat. The engine is the primary source of energy in automobiles, and augmentation in performance of its cooling system is of great importance, as it carries secondary heat from the engine and dissipates it to the surrounding [1]. Cooling of systems is standout amongst the most essential specialized difficulties confronted by various businesses such as automobiles, electronics and manufacturing industry [2]. New technologies in electronic devices need efficient heat

Syed Mohd. Yahya, smyahya@zhcet.ac.in | 'Sustainable Energy and Acoustic Research Laboratory, Department of Mechanical Engineering, Aligarh Muslim University, Aligarh, India. ${ }^{2}$ Department of Mechanical Engineering, Integral University, Lucknow, India. 
management as it contains high heat generating circuits in it [3].

Water is traditionally used as a radiator coolant in automobiles under normal conditions. Ethylene glycol (EG)-water blend and motor oil slightly bettered the cooling performance compared to water. However, the current industrial standards necessitate a more reliable and lasting solution to achieve better heat transfer features in automobiles with enhanced heat dissipation leading to improved efficiency. With modern technologies, need to improve heat transfer with the help of nanocoolants become more significant [4]. It could be beneficial for automobile cooling system to replace mediocre cooling medium with nanocoolants. After adding different nanoparticles into these coolants, their cooling capacity increases [5]. These improvements are useful to evacuate heat from the system with the help of cooling system, generally of smaller size. The result of smaller coolant system contributes to decrease in engine load up to a certain level [6]. So that light motor group can also achieve effectiveness [7]. Size of nanoparticles is between 1 and $100 \mathrm{~nm}$ which is very small due to which no compromise in pumping power was observed [8]. Suspending nanoparticles improves the heat conveying ability of coolants with negligible or no pressure drop [9]. A definitive purpose or objective of nanocoolants is to accomplish the most astounding thermal properties at least practicable concentration of nanoparticles through proper scattering and stable suspension in base fluid [10]. Thermal properties of fluid, holds the supreme role in heating as well as in cooling applications nowadays [11]. Essentially, present-day nanotechnology provides a physical and chemical method for the preparation of nanometer sized particles or nano-organized substances, produced on nuclear or sub-atomical scales with enhanced thermo-physical properties, in comparison to their distinct mass structures [12]. Estimation of the heat transfer coefficient of nanofluids is a vital stream trademark in deciding the implementation of nanoparticles in base fluid. Increment in the heat transfer coefficient of the nanofluids improves the heat transfer rate. Since Choi [8] presented the idea of nanofluids, various research groups started dealing with the estimation of thermal and rheological properties of water-based nanofluids for various applications including transportation, electronic cooling, energy generation, vehicle motors, nuclear reactors, energy efficiency upgrade and biomedical applications [13]. Eastman et.al. [14] Experimentally demonstrated the anomalous enhancement of thermal conductivity of copper nanofluids when mixed with Ethylene glycol. Speculations persists for the causes of this behavior. However, Brownian motion, loose agglomerates, hydration layer around the particles was suggested as few possible mechanism to explain the improvement in thermal conductivity of nanofluids [15]. The nanoparticles small size $(<100 \mathrm{~nm})$ and large specific surface area results in the long term stability, homogeneity with minimal clogging in the flow passage. [16].

Nieh et al. [17] carried out investigation in an air-cooled radiator to enhance its performance by using $\mathrm{TiO}_{2}$ and $\mathrm{Al}_{2} \mathrm{O}_{3}$-wate/EG nanocoolant. Differernt concentration $(0.5,1.0,2.0 \mathrm{wt} . \%)$ nanocoolant were prepared by two step method. Reported results evaluated that $\mathrm{TiO}_{2}$ based nanocoolant has higher heat removal capacity than $\mathrm{Al}_{2} \mathrm{O}_{3}$ based nanocoolant. Maximum enhancement for heat dissipation capacity was $25.6 \%$. Naraki et al. [18] conducted experiments in radiator of car to evaluate HTC of $\mathrm{CuO} /$ water nanofluid. Different concentration $(0.15,0.4 \mathrm{vol} . \%)$ nanofluid were prepared, for stability test was also conducted with different PH. Maximum HTC value was recorded for 0.4 vol.\% nanofluid with $8 \%$ enhancement compared to base fluid. Bhimani et al. [19] conducted experiment with low concentration nanofluid in automobile radiator to compare heat transfer coefficient of water and $\mathrm{TiO}_{2}$ based nanofluid. Nanofluid with 1 vol.\% concentration shows 40-45\% enhancement in heat transfer. Peyghambarzadeh et al. [20] conducted experiment in automotive radiator with $\mathrm{Al}_{2} \mathrm{O}_{3}$ /water and $\mathrm{Al}_{2} \mathrm{O}_{3}$ /Ethylene-glycol based nanofluids. Different concentration nanofluid were prepared $(0.2,0.4,0.6,0.8,1.0$ vol.\%) and heat transfer enhancement of $40 \%$ was recorded compared to water. Flowrate ranges from 2 to $6 \mathrm{~L} / \mathrm{min}$. Leong et al. [21] tested copper nanoparticle with concentration ranging from 0 to 2 vol.\% in ethylene glycol based nanofluid in radiator of car. 3.8\% enhancement in heat transfer was achieved with $2 \%$ copper particle. Oliveira et al. [22] conducted experiment for the study of MWCNT- water based nanofluid in automotive radiator. Experimental setup consist of wind tunnel that help in generating air flow across radiator at the rate of $0.175 \mathrm{~kg} / \mathrm{s}$. Nanoparticle concentration varied from 0.05 to $0.16 \%$. The decrease in heat transfer rate was observed for all test condition.

It is obvious from the above literature that nanofluid was used as a coolant for different thermal systems as well as in engine cooling. However less literature is available for cooling of engine from radiator with low concentration nanocoolants. In this paper the potential capabilities of nanoparticles to enhance the heat transfer by increasing the thermal conductivity of nanocoolant is utilized and is used in conjunction with conventional coolants. The point is to examine the study of the nanocoolants as a coolant in the radiator tubes for the heat transfer and to research the heat transfer enhancement using $\mathrm{T}_{\mathrm{i}} \mathrm{O}_{2}$ nanoparticles having diameter $\sim 15 \mathrm{~nm}$ with different volume concentrations i.e. $0.01 \%, 0.03 \%$ and $0.05 \%$ in water $-E G$ as the base fluid. 
Imminent section includes: materials, preparation of nanocoolants, experimental setup and methodology to find out the heat transfer, discussion on the finding of different concentration nanocoolants and their comparison with other conventional coolants.

\section{Material and methods}

The two-step approach is the most used strategy for preparing nanofluids. Nanoparticles, nanofibers, nanotubes, or other nanomaterials utilized in this technique are first created as dry powders by chemical or physical methods like grinding, laser ablation, sol-gel processing and so forth. After this, the nanopowder is scattered into the liquid in the second preparation activity with the assistance of intensive magnetic force agitation or ultrasonic agitation [11]. This method is the most economically feasible technique for preparing nanocoolant at a substantial scale. The imperative procedure to improve the stability of nanoparticles in liquids is the utilization of surfactants. Nonetheless, the usefulness of the surfactants under high temperature is additionally a major concern [23]. The material of nanoparticles is picked as $\mathrm{T}_{\mathrm{i}} \mathrm{O}_{2}$ since it is synthetically steady and its expense is not as much as its metallic counterpart and furthermore effectively accessible [24]. The two-step method applies better for nanofluids containing oxide nanoparticles and size of $\mathrm{TiO}_{2}$ particle used for this work was $15 \mathrm{~nm}$, in this way nanofluids containing $\mathrm{T}_{\mathrm{i}} \mathrm{O}_{2}$ particle were prepared by two-step method. The nanofluid utilized in the present work was prepared by utilizing $25 \%$ of ethylene glycol (EG) and $75 \%$ of water. The concentration of nanoparticle added to the base fluid was evaluated using Eq. (1) [25].

Volume Concentration, $\phi=\left[\frac{\frac{W_{\text {particle }}}{\rho_{\text {particle }}}}{\frac{W_{\text {particle }}}{\rho_{\text {particle }}}+\frac{W_{\text {flud }}}{\rho_{\text {fluid }}}}\right]$

The synthesized nanofluid was first stirred in magnetic stirrer for about $1.5 \mathrm{~h}$ and then kept in an ultrasonic bath continuously for $90 \mathrm{~min}$. However, a surfactant SDBS (Sodium Dodecyl Benzene Sulfonate) was used. SDBS with weight equal to1/10th weight of the nanoparticles was used. The bulk volumetric concentrations of $0.01 \%, 0.03 \%$ and $0.05 \%$ nanoparticle for $5.5 \mathrm{~L}$ capacity were utilized for the present examination. Ultrasonic bath was used for sonicating nanoparticles in base fluid as shown in Fig. 1.

\subsection{Experimental setup and formula used}

In this experiment, different devices were assembled to complete the setup which includes 4-S diesel engine of capacity $3.75 \mathrm{~kW}$, framework also consist of 8-K type

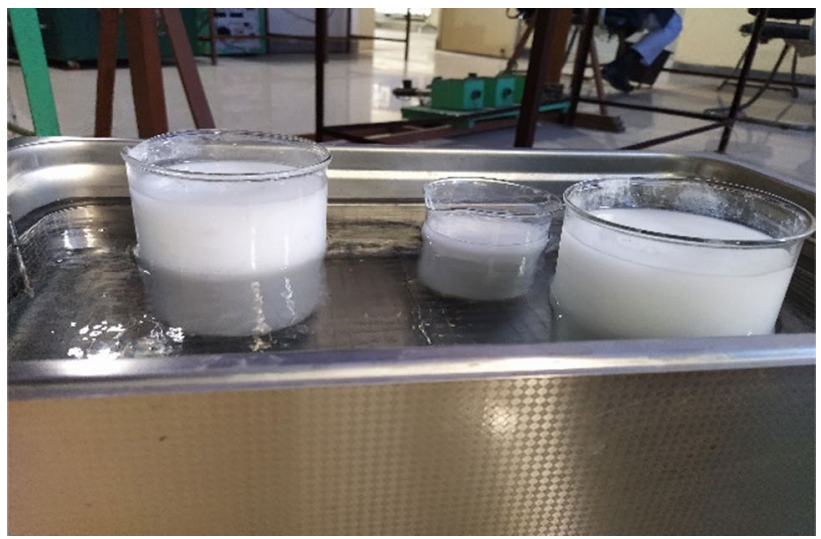

Fig. 1 Sonication process

and 2 wire type thermocouples. A display for indicating temperature and a rotameter for measuring the flowrate of nanocoolants were also used during the study. Initially, the fluid (coolant) at its room condition was allowed to pass and pick heat from the engine and in this temperature of the fluid raised. This flow of nanocoolant repeated continuously, until steady state is achieved after which no further rise in temperature was observed. At this point the temperature at the inlet of radiator (i.e. engine outlet) was recorded. There is a fan at one side of the radiator, which sucks the ambient air through the outer periphery of radiator tubes. The heated fluid enters the radiator's tube and thus, heat gets convected from the central axis towards the inner periphery of the tube simultaneously in all the tubes (60 tubes). The thickness of the tubes $(0.04 \mathrm{~mm})$ was so small and it is made up of highly conducting material (i.e. copper), due to which temperature difference between inner and outer surface of tubes walls become infinitesimally small and it was assumed that both surface are at same temperature [26].

Now, the heat gets convected from the outer surface of the tube to the surrounding air, by passing air tall 60 -tubes of the radiator with the help of a fan. So that heat transfer can be calculated from flowing fluid to the surface of the tube. At this point, average heat transfer coefficient plays an important role. This property ensures that the amount of heat removal for a unit surface area in contact with the fluid is proportional to the unit temperature drop. More is the value of heat transfer coefficient for coolant, more will be the heat transfer rate [27]. Calibrate thermocouples by correlating it with standard thermometers by immersed theming stirred water or oil baths. The specific points are calibrated with respect to reference temperature baths, for example, a blend of squashed ice and water. Observe the changes at different temperatures and record the errors (Figs. 2, 3, 4, 5, 6). 
Fig. 2 Different view of experimental setup
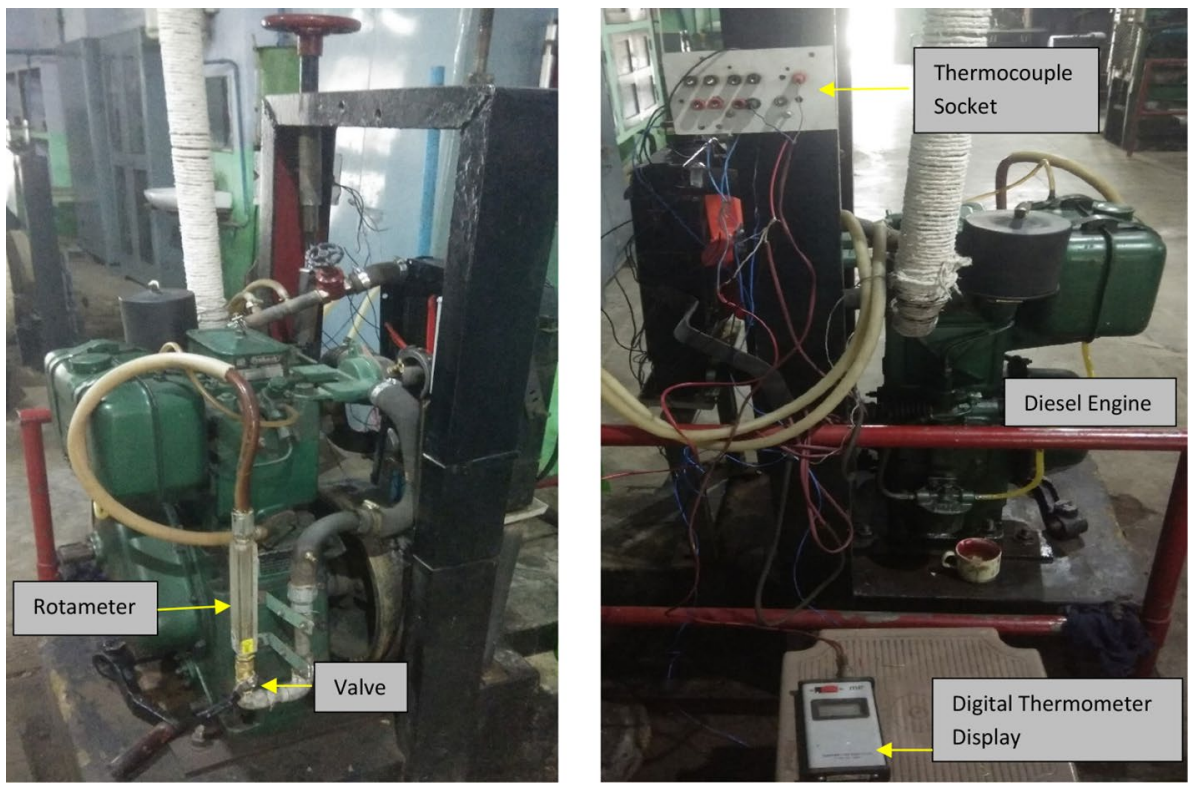

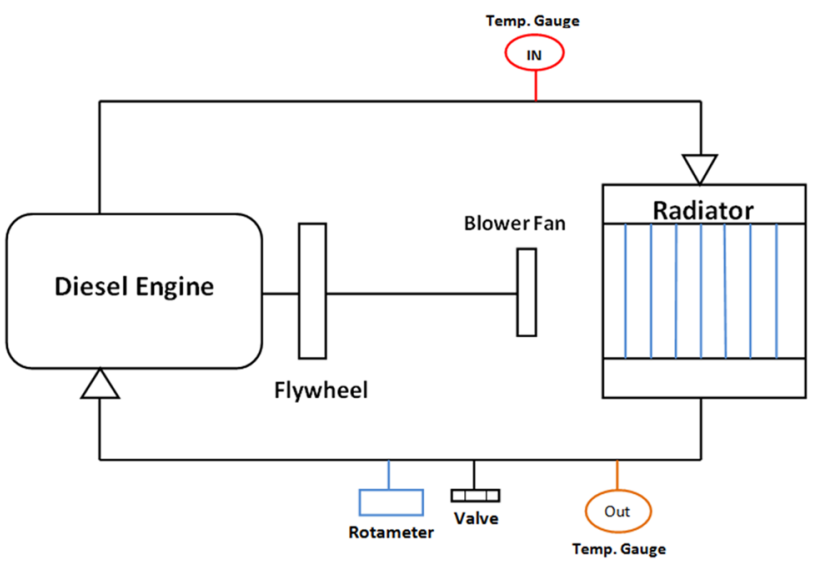

Fig. 3 Schematic line diagram of the experimental setup

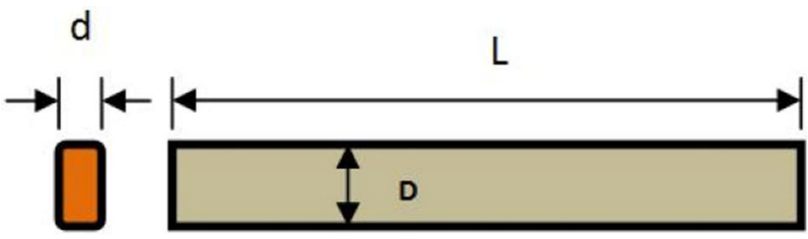

Fig. 4 Flat tube of radiator

It can be easily concluded that error in the measurement of temperature with the help of thermocouple is in the range of $0-3 \%$. Hence, thermocouple can be used to measure temperature.

Various considerations have been made with respect to the operating conditions of the diesel engine cooling system: Steady-state, incompressible and Newtonian laminar

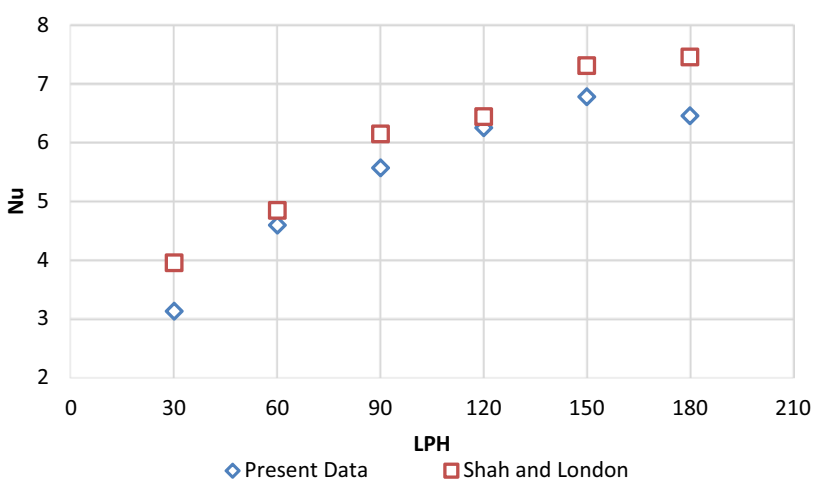

Fig. 5 Nusselt number at different LPH for pure water

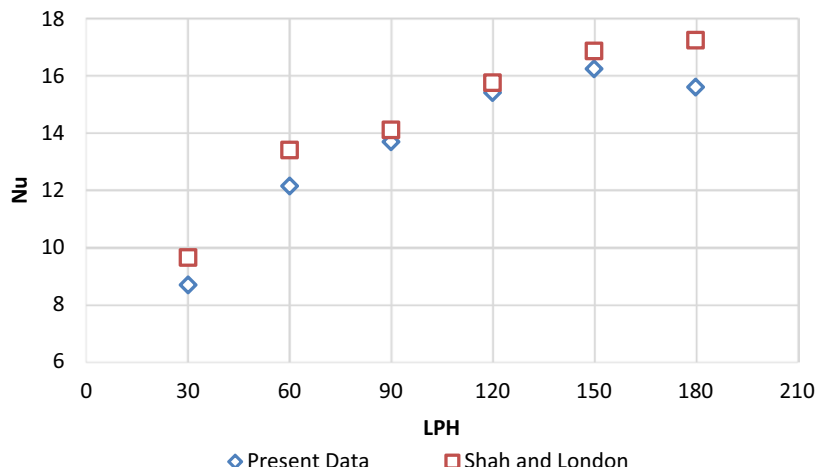

Fig. 6 Nusselt number at different LPH for TiO2/EG-Water nanofluid $(0.03 \%$ by volume)

\section{SN Applied Sciences}


Table 1 Error in temperature measuring device

\begin{tabular}{llll}
\hline S. No & $\begin{array}{l}\text { Mercury-in-glass } \\
\text { thermometer }\end{array}$ & Thermocouple & Error (\%) \\
\hline 1 & $0{ }^{\circ} \mathrm{C}$ & $0{ }^{\circ} \mathrm{C}$ & 0 \\
2 & $18.5^{\circ} \mathrm{C}$ & $18^{\circ} \mathrm{C}$ & 2.7 \\
3 & $44^{\circ} \mathrm{C}$ & $43^{\circ} \mathrm{C}$ & 2.27 \\
4 & $73.5^{\circ} \mathrm{C}$ & $73^{\circ} \mathrm{C}$ & 0.68 \\
\hline
\end{tabular}

liquid streams with consistent thermophysical properties of the nanofluid. Moreover, conduction of heat in the axial direction and wall thickness of the tubes of radiator was neglected. Vehicle radiator utilized for this experiment, comprises of numerous flat tubes of each length $(L=307.34 \mathrm{~mm})$ and hydraulic diameter $\left(D_{h}=3.92 \mathrm{~mm}\right)$. The Reynolds number was determined by using the term i.e. hydraulic diameter $\left(D_{h}\right)$, given by Eq. (2).

$D_{h}=\frac{4 \times\left[\frac{\pi}{4} d^{2}+(D-d) \times d\right]}{\pi \times d+2 \times(D-d)}$

Heat transfer by bulk of the coolant is measured using Eq. (3).

$\mathrm{Q}=\dot{\mathrm{m}} \mathrm{C}_{\mathrm{p}} \Delta \mathrm{T}=\dot{\mathrm{m}} \mathrm{C}_{\mathrm{p}}\left(\mathrm{T}_{\text {in }}-\mathrm{T}_{\text {out }}\right)$

where, $\dot{m}$ is the mass flow rate of fluid $(\mathrm{Kg} / \mathrm{s}), C_{p}$ is the specific heat at constant pressure $\left(\mathrm{J} / \mathrm{Kg}-{ }^{\circ} \mathrm{K}\right), \mathrm{T}_{\text {in }}$ is the inlet temperature of fluid to the radiator and $\mathrm{T}_{\text {out }}$ is the outlet temperature of fluid from radiator. Transmission of heat to atmosphere is given by Eq. (4).

$\mathrm{Q}=\mathrm{hA} \Delta \mathrm{T}=\mathrm{hA}\left(\mathrm{T}_{\mathrm{b}}-\mathrm{T}_{\mathrm{w}}\right)$

where, $\mathrm{h}$ is the Convective Heat Transfer Coefficient (W/ $\left.\mathrm{m}^{2}-\mathrm{K}\right), \mathrm{A}$ is the Area of the Tube from which transfer of heat takes place, $T_{b}$ is the Bulk Temperature of the Fluid, and $T_{w}$ is the Wall Temperature of the tubes of the Radiator.

Nusselt Number, $\mathrm{Nu}=\frac{h D_{h}}{K}$ where, $D_{h}$ is the Hydraulic Diameter of the tube, $K$ is the Thermal Conductivity of flowing fluid $\left(\mathrm{W} / \mathrm{m}-{ }^{\circ} \mathrm{K}\right)$.

$R e=\frac{\rho V D_{h}}{\mu}$

Where, 'Re' is the Reynolds number, ' $V$ ' is the velocity of the flow, ' $D_{h}{ }^{\prime}$ is the hydraulic diameter of tube and ' $\mu$ ' is the dynamic viscosity of the fluid (Table 1).

Table 2 shows the uncertainty analysis for different instruments used in this work.

\section{Results and discussion}

\subsection{Reliability test of the apparatus used}

In this study, to validate the experimental setup, experiments were conducted with pure water and nanocoolant $(0.03 \%$ concentration) in tube of radiator. The experimental results showed reasonable agreement with Shah and London equation [28].

$N u=1.953\left(\operatorname{RePr} \frac{D}{L}\right)^{1 / 3}$ for $\operatorname{RePr} \frac{D}{L} \geq 33.33$

$N u=4.364+0.0722\left(\operatorname{Re} \operatorname{Pr} \frac{D}{L}\right)$ for $\operatorname{Re} \operatorname{Pr} \frac{D}{L} \leq 33.33$

\subsection{Heat transfer study}

Initially, water is used as a coolant to absorb heat from the engine and transfer it to the surroundings while flowing through the tubes of the radiator. In Fig. 7, it can be seen that the convective heat transfer coefficient is increasing along the volume flow rate (LPH) and attaining a maximum value at $150 \mathrm{LPH}$ and then there is slight decrease. At the start, there is a sharp increase in convective heat transfer coefficient (i.e. $46 \%$ enhancement) but after that, enhancement becomes gradual. It can be noticed from Fig. 8 that the heat transferred from coolant to the atmosphere increases and attains a maximum value and then decrease. At 150 LPH (Volume Flow Rate), maximum

Table 2 Uncertainty analysis

\begin{tabular}{|c|c|c|c|c|c|c|c|}
\hline \multirow[t]{2}{*}{ S. No } & \multirow[t]{2}{*}{ Name of the instruments } & \multirow[t]{2}{*}{ Range of instrument } & \multirow[t]{2}{*}{ Variables measured } & \multicolumn{2}{|c|}{$\begin{array}{l}\text { Values measured in } \\
\text { experiment }\end{array}$} & \multicolumn{2}{|c|}{$\%$ uncertainty } \\
\hline & & & & Min & Max & Min & Max \\
\hline 1 & K-Type thermocouple & $0-200{ }^{\circ} \mathrm{C}$ & Bulk temperature, $T_{b}$ & 43 & 67 & 0.7463 & 1.1628 \\
\hline 2 & Wire thermocouple & $0-200{ }^{\circ} \mathrm{C}$ & Wall temperature, $T_{w}$ & 41 & 63 & 0.7937 & 1.2195 \\
\hline 3 & Rotameter & 0-10 LPM & Volume flow rate & 0.5 & 3 & 0.3334 & 2 \\
\hline
\end{tabular}




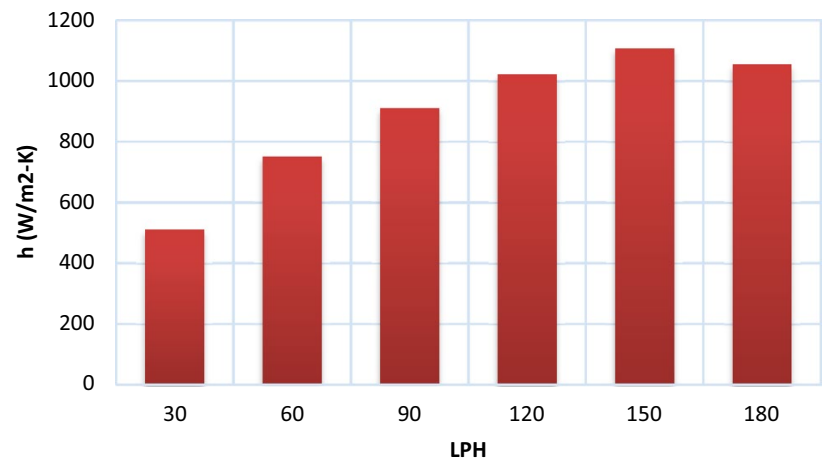

Fig. 7 Heat Transfer Coefficient against volume flow rate for water

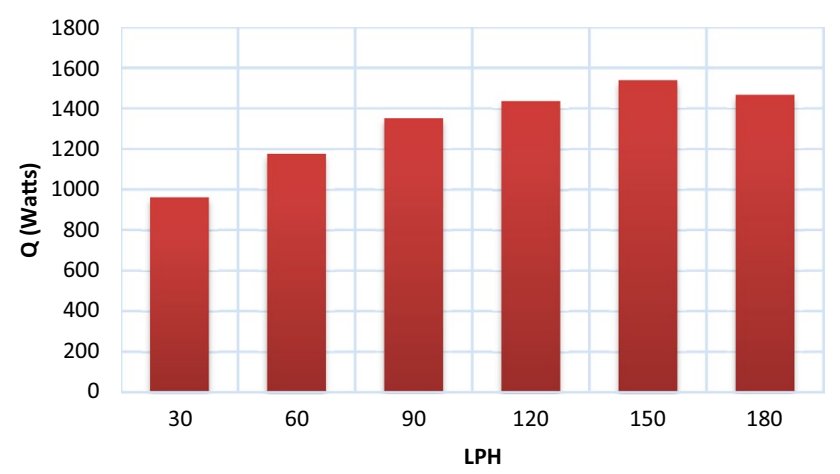

Fig. 8 Heat transfer against volume flow rate for water

rate of heat transfer is achieved. Enhancement of heat transfer is $60 \%$ when compared with the least amount of heat transfer by this coolant (i.e. water). Reduction in the heat transfer coefficient and heat transfer after $150 \mathrm{LPH}$ is because of less time given to fluid at high flow rate to absorb or reject heat.

Difference between radiator's inlet and outlet temperature $\left(T_{\text {in }}-T_{\text {out }}\right)$ with respect to volume flow rate is shown in Fig. 9. As we can in Fig. 7 that $\Delta T$ is maximum for volume flow rate of $30 \mathrm{LPH}$. The reason for this trend is clear that at low volume flow rate time taken by coolant to absorb or reject heat, from engine to the surrounding is more. At low flow rate time given to coolant to exchange heat is more as compared to coolant at high flow rate. So time taken by coolant to flow plays an important role in heat exchange process. If heat exchanging medium does not get proper time to communicate with another medium, there is a probability of unsuccessful heat transfer.

Figure 10 shows different concentration $\mathrm{TiO}_{2}$ nanocoolants performance by improving the heat transfer coefficient at different volume flow rate. It is clearly concluded that increasing the velocity of coolant in radiator tubes increases the heat transfer coefficient. Hence, velocity

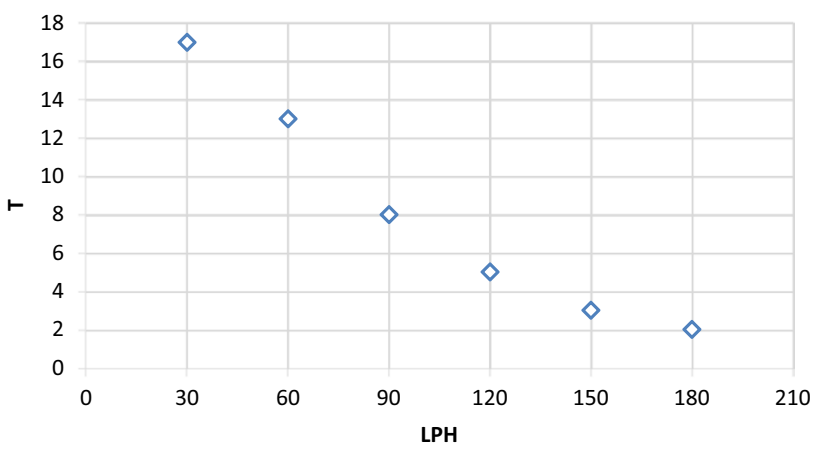

Fig. $9\left(\mathrm{~T}_{\text {in }}-\mathrm{T}_{\text {out }}\right)$ against volume flow rate

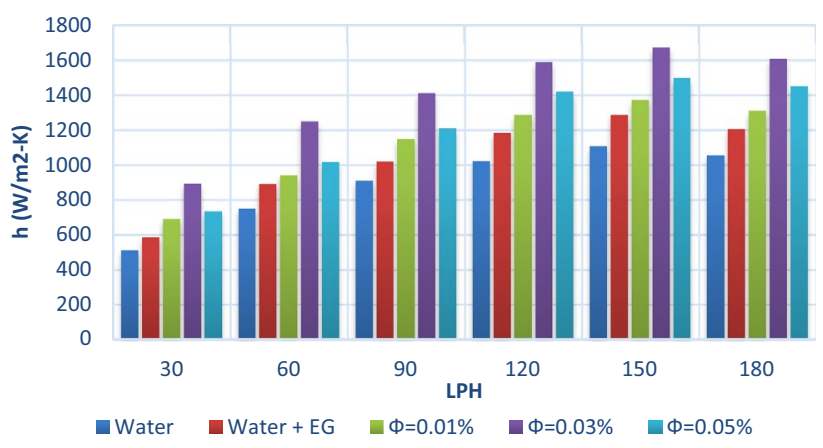

Fig. 10 Convective heat transfer coefficient for different coolants at different flow rate

of coolant plays an important role in increasing the heat transfer coefficient. Compared to water and water-EG combination, all different concentration nanocoolants performs better at corresponding flow rates. Nanocoolant with particle concentration $0.03 \%$ gives the best results, it may be because beyond this concentration nanocoolant stability reduced. The reason for this enhancement in the value of heat transfer coefficient is because of increase in thermal conductivity of nanocoolant with addition of nanoparticle into the base fluid [29].

In Fig. 11, $\Delta \mathrm{T}$ for different coolants has been compared corresponding to the volume flow rates. It cannot be clearly said by comparing water and water-EG, that which among them shows the highest value of $\Delta T$ at $30 \mathrm{LPH}$. Whereas from 60 to $180 \mathrm{LPH}$ water-EG combination gives greater value of $\Delta T$ compared to water. The reason for higher value $\Delta T$ is less heat capacity of water-EG compared to only water. Ultimately, $\varphi=0.03 \%$ nanocoolant has the maximum $\Delta \mathrm{T}$ corresponding to all flow rates when compared with other coolants. Maximum enhancement of $100 \%$ was observed at $120 \mathrm{LPH}$ and $150 \mathrm{LPH}$ in the value of $\Delta T$ when compared nanocoolant $(\varphi=0.03 \%)$ with water. In Fig. 12, outlet temperature is plotted against the volume flow rates. Increasing the flow rate of nanocoolants, 


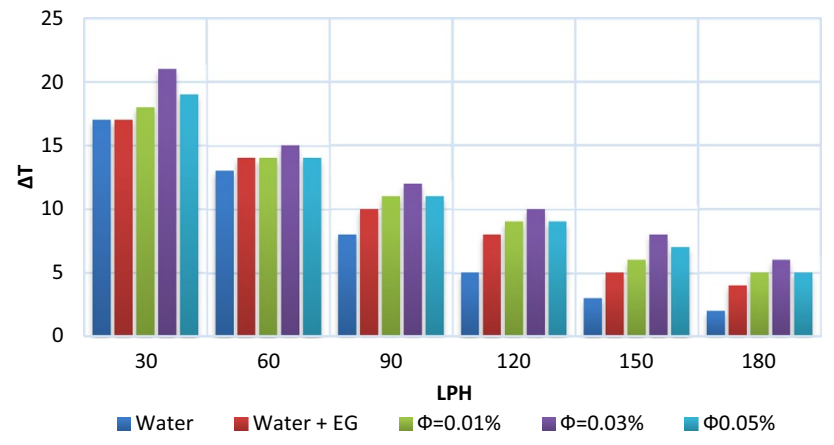

Fig. $11 \Delta \mathrm{T}\left(\mathrm{T}_{\text {in }}-\mathrm{T}_{\text {out }}\right)$ for different coolants for different flow rates

increased the temperature of fluid coming from radiator outlet. Therefore there is a direct relationship between fluids flow rate and outlet temperature. The reason for this increase in temperature is that, at high flow rate fluid didn't get enough time to exchange heat. For different volume flow rates, radiator outlet temperature is maximum for water. Because of high heat capacity of water it was unable to drop the temperature value at the outlet of the radiator as compared to other coolants. Same relationship between outlet temperature and fluid flow rate was published and reported by Heris et al. [30].

In Fig. 13, the heat transfer ratio of different volume concentration nanocoolants with respect to base fluid at different volume flow rate has been shown. With the little addition of nanoparticle $(0.03 \%)$, heat transfer increase is clearly observed. Corresponding to $0.03 \%$ concentration, maximum enhancement of 1.295 times is observed at 150 LPH. Hence, $29.5 \%$ of maximum heat transfer is achieved here as compared to base fluid. There was continuous removal of heat from diesel engine to the surrounding. Enhancement in heat transfer with nanocoolant at different volume flow rate was observed. The reason for this improvement in heat transfer is reduction in heat capacity of nanocoolant. Hence, it exchange heat more rapidly as compared to water and water-EG mixture. Maximum

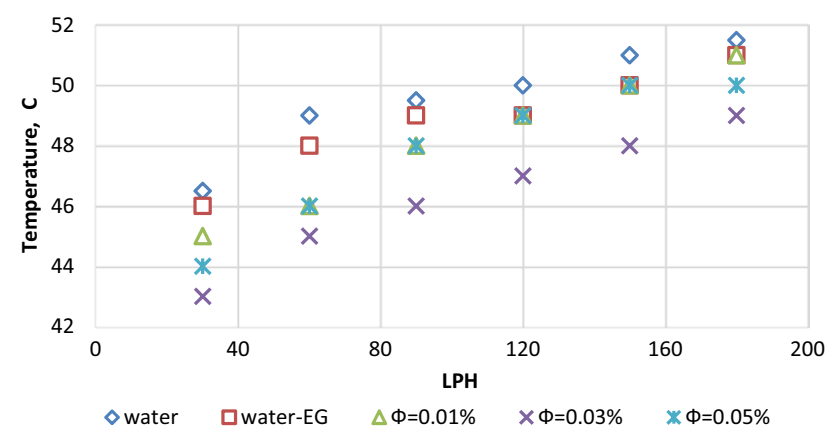

Fig. $12 \mathrm{~T}_{\text {out }}$ versus volume flow rates

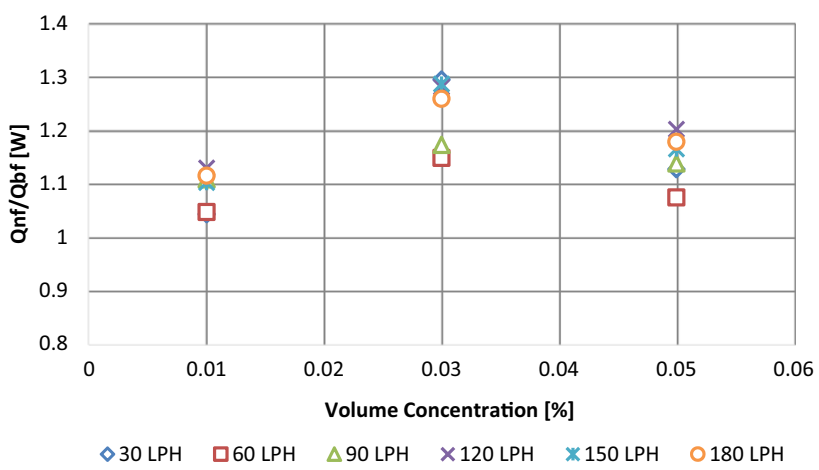

Fig. 13 Heat transfer enhancement versus coolant with different concentration

enhancement is recorded for $0.03 \% \mathrm{~T}_{\mathrm{i}} \mathrm{O}_{2}$ particle concentration in water-EG mixture. Similar study of heat transfer enhancement with volume flow rate has been reported by Ali et al. [31].

Involvement of nanocoolant in the radiator tubes shows enhancement in heat removal capacity as compared to base fluid. Hence, nanocoolants posses' great potential in removal of heat from high heat generating equipment's. Also because they are nanometer sized particle, they can be easily used in MEMS (micro-electromechanical system) to improve their efficiency.

From results of this experiment it is also concluded that low concentration nanocoolants plays an important role in heat transfer improvement. CFD analysis can also be done in future to compare the results with experimental data.

\section{Conclusion}

In radiator, for the purpose of heat transfer, conventional coolant such as water was being used, and also the mixture of water and other coolant like ethylene glycol was utilized. But, the latest development in the field of nanofluids has achieved great milestone in heat transfer. For this study, water with ethylene glycol (75:25 by volume) used as the base fluid and $\mathrm{T}_{i} \mathrm{O}_{2}$ nanoparticles were mixed in it, to develop different concentration nanocoolants. The results obtained from nanocoolants are better as compared to water and mixture of water-EG. Nanocoolant with $0.03 \%$ of $\mathrm{T}_{i} \mathrm{O}_{2}$ volume fraction shows maximum enhancement of heat transfer as well as heat transfer coefficient compared with other coolants. $29.5 \%$ enhancement in the value of heat transfer ' $Q$ ' was recorded for nanocoolant with $0.03 \%$ particle volume concentration, which is overall maximum. This is due to the increase in thermal conductivity and heat transfer coefficient of prepared nanocoolant. The temperature difference between inlet and outlet of radiator was maximum for nanocoolants when compared 
to water and water-EG mixture. This clearly indicates that nanocoolants has higher heat removal capacity than pure water and water-EG mixture. Temperature at outlet of the radiator is least for nanocoolant with $0.03 \%$ nanoparticle concentration corresponding to all the volume flow rates. Suspending nanoparticle in the base fluid shows enhancement in coolants heat removal capacity as well as assured usage of nanocoolants in engine radiator and other heat exchange devices. This better enhancement of heat removal from engine leads to smaller size and also reduction in the manufacturing cost of the radiator. Limitations of this work includes cost of preparing nanocoolants, less stability of nancoolants for longer period of time, accumulation of nanoparticle with passage of time. Cost of preparing nanocoolant are some of the other challenges faced during the time of preparing it.

Future scope: $\mathrm{T}_{\mathrm{i}} \mathrm{O}_{2}$ nanoparticle of size $15 \mathrm{~nm}$ was used to synthesis different concentration nanocoolants. Hence, this work may be further extended using different shapes, size, type, concentration of nanoparticle in the base fluid. Also method of synthesizing nanocoolant may be different.

\section{Declarations}

Conflict of interest The authors declare that they have no conflict of interest.

Open Access This article is licensed under a Creative Commons Attribution 4.0 International License, which permits use, sharing, adaptation, distribution and reproduction in any medium or format, as long as you give appropriate credit to the original author(s) and the source, provide a link to the Creative Commons licence, and indicate if changes were made. The images or other third party material in this article are included in the article's Creative Commons licence, unless indicated otherwise in a credit line to the material. If material is not included in the article's Creative Commons licence and your intended use is not permitted by statutory regulation or exceeds the permitted use, you will need to obtain permission directly from the copyright holder. To view a copy of this licence, visit http://creativecommons .org/licenses/by/4.0/.

\section{References}

1. Jinsiwale N, Achwal V (2018) Heart transfer enhancement in automobile radiator using nanofluids: a review". Int J Eng Trends Tech 55(2):68-74

2. Ali M, Al-Sofyany Z (2014) The effect of nanofluid concentration on the cooling system of vehicles radiator. Adv Mech Eng. https ://doi.org/10.1155/2014/962510

3. Jang S, Choi S (2006) Cooling performance of a microchannel heat sink with nanofluids. Appl Therm Eng 26(17):2457-2463

4. Wang X, Majumdar A (2008) A review on nanofluids part II experiments and applications. Braz J Chem Eng 25(4):631-648. https ://doi.org/10.1590/S0104-66322
5. Safaei MR et al (2020) Thermal analysis of a binary base fluid in pool boiling system of glycol-water alumina nano-suspension. $J$ Therm Anal Calorim. https://doi.org/10.1007/s10973-020-09911 $-5$

6. Sarafraz MM, Safaei MR, Tian Z, Goodarzi M (2019) Nano suspension in a compact heat exchanger. Energies 12(10):1929

7. Li ZX, Khaled U, Al-Rashed AAAA, Goodarzi M, Sarafraz MM, Meer R (2020) Heat transfer evaluation of a micro heat exchanger cooling with spherical carbon-acetone nanofluid. Int J Heat Mass Transf. https://doi.org/10.1016/j.ijheatmasstrans fer.2019.119124

8. Choi SUS (1995) Enhancing thermal conductivity of fluids with nanoparticles developments and applications of non-newtonian flows. ASME 38(2):99-105

9. Tian Z et al (2019) Turbulent flows in a spiral double-pipe heat exchanger: Optimal performance conditions using an enhanced genetic algorithm. Int J Numer Methods Heat Fluid Flow 30(1):39-53. https://doi.org/10.1108/HFF-04-2019-0287

10. Li X, Zou C, Qi A (2016) Experimental study on the thermophysical properties of car engine coolant (water/ethylene glycol mixture type) based SiC nanofluids. Int Commun Heat Mass Transf 77(3):159-164

11. Saidur R, Leong K, Mohammed H (2011) A review on applications and challenges of nanofluids. Renew Sustain Energy 15(1):1646-1668

12. Giwa SO, Sharifpur M, Goodarzi M, Alsulami H, Meyer JP (2020) Influence of base fluid, temperature, and concentration on the thermophysical properties of hybrid nanofluids of aluminaferrofluid experimental data, modeling through enhanced ANN, ANFIS, and curve fitting. J Therm Anal Calorim. https:// doi.org/10.1007/s10973-020-09372-w

13. Goodarzi M et al (2016) Investigation of heat transfer performance and friction factor of a counter-flow double-pipe heat exchanger using nitrogen-doped, graphene-based nanofluids. Int Commun Heat Mass Transf 76:16-23. https://doi. org/10.1016/j.icheatmasstransfer.2016.05.018

14. Eastman JA, Choi US, Li S, Yu W, Thompson LJ (2001) Anomalously increased effective thermal conductivities of ethylene glycol-based nanofluids containing copper nanoparticles. Appl Phys Lett 78:718

15. Danish M, Yahya SM, Saha BB (2019) Modelling and optimization of thermophysical properties of aqueous titania nanofluid using response surface methodology. J Therm Anal Calorim. https://doi.org/10.1007/s10973-019-08673-z

16. Abhishek S, Yahya SM, Ansari MA, Saleem AK (2019) Role of 1-butanol on critical heat flux enhancement of TiO2, Al2O3 and CuO Nanofluids. J Nanofluids 8(7):1560-1565

17. Nieh $H$, Teng T, Yu C (2014) Enhanced heat dissipation of a radiator using oxide nano-coolant". Int J Therm Sci 77:252-261

18. Naraki M, Peyghambarzadeh S, Hashemabadi S (2013) Parametric study of overall heat transfer coefficient of $\mathrm{CuO}$ water nanofluids in a car radiator. Int J Therm Sci 66:82-90

19. Bhimani V, Rathod P, Sorathiya A (2013) Experimental study of heat transfer enhancement using water based nanofluids as a new coolant for car radiators. Int J Emerg Technol Adv Eng 3(6):295-302

20. Peyghambarzadeh S, Hashemabadi S (2011) Experimental study of heat transfer enhancement using water/ethylene glycol based nanofluids as a new coolant for car radiators. Int Commun Heat Mass Transfer 38:1283-1290

21. Leong K, Saidur R, Kazi S, Mamun A (2010) Performance investigation of an automotive car radiator operated with nanofluid-based coolants (nanofluid as a coolant in a radiator). Appl Therm Eng 30:2685-2692 
22. Oliveira G, Contreras E (2017) Experimental study on the heat transfer of MWCNT/water nanofluid flowing in a car radiator. Appl Therm Eng 111:1450-1456

23. Elsebay M, Elbadawy I, Shedid M, Fatouh M (2016) Numerical resizing study of $\mathrm{Al} 2 \mathrm{O} 3$ and $\mathrm{CuO}$ nanofluids in the flat tubes of a radiator. Appl Math Model 40:6437-6450

24. Elias M, Mahbubul I, Saidur R, Sohel M, Shahrul I, Khaleduzzaman S (2014) Experimental investigation on the thermophysical properties of $\mathrm{Al} 2 \mathrm{O} 3$ nanoparticles suspended in car radiator coolant. Int Commun Heat Mass Transf 54:48-53

25. Devireddy S, Mekala CSR, Veeredhi VR (2016) Improving the cooling performance of automobile radiator with ethylene glycol water based $\mathrm{TiO} 2$ nanofluids. Int Commun Heat Mass Transf 78:121-126. https://doi.org/10.1016/j.icheatmasstrans fer.2016.09.002

26. Ansari S, Hussain T, Yahya SM, Chaturvedi P, Sardar N (2018) Experimental investigation of viscosity of nanofluids containing oxide nanoparticles at varying shear rate. J Nanofluids 7:1075-1080

27. Brinkman HC (1952) The Viscosity of Concentrated Suspensions and Solutions. J Chem Phys 20(4):571-571
28. Shah RK (1975) Thermal entry length solutions for the circular tube and parallel plates. Natl Heat Mass Transf conf 1:11-75

29. Murshed SMS, Leong KC, Yang C (2005) Enhanced thermal conductivity of $\mathrm{TiO} 2$ - Water based nanofluids. Int J Therm Sci 44(4):367-373. https://doi.org/10.1016/j.ijthermals ci.2004.12.005

30. Zeinali Heris S, Shokrgozar M, Poorpharhang S, Shanbedi M, Noie SH (2014) Experimental study of heat transfer of a car radiator with $\mathrm{CuO} /$ Ethylene glycol-water as a coolant. J Dispersion Sci Technol 35(5):677-684. https://doi.org/10.1080/01932 691.2013.805301

31. Ali $\mathrm{H}$, Liaquat $\mathrm{H}$, Maqsood $\mathrm{H}$, Nadir $\mathrm{M}$ (2015) Experimental investigation of convective heat transfer augmentation for car radiator using $\mathrm{ZnO}$-water nanofluids. Energy 84:317-324

Publisher's Note Springer Nature remains neutral with regard to jurisdictional claims in published maps and institutional affiliations. 